\title{
The Origins of Human Swarm Problem Solving
}

\section{I Background}

In human evolution, it is likely that important transitions in group organization, both increases in group size and new types of cooperation between human groups, were motivated by attempts to solve problems more effectively. It is here suggested that it was the gradual evolution from small group cooperation to interaction in large groups that eventually made human swarm problem solving possible. But how did this process unfold in evolution? This is a hard question to answer, and this chapter will only briefly address the issue by highlighting a few of the historical milestones that are considered important antecedents.

If we look back in time, most researchers agree that group hunting of large animals is an important achievement in human history. This new practice made it possible to gain access to more food. Group hunting also resembles the basic characteristics of human swarm problem solving with its emphasis on rapid problem solving, specific interactional rules, and the involvement of all group members. Although group hunting required some degree of planning and higher-order cognition, it is plausible that the first type of group hunting resembles how other animal groups hunt together.

A second major milestone was the establishment of peaceful interaction between different human groups or communities. In evolution, this is a major achievement, as we know that our close relatives, the chimpanzees, do not trust strangers. It is likely that this first interaction with strangers across groups began through trade. Collective problem solving between groups made it possible to utilize informational diversity from nonkin and even strangers, and must have amplified human learning, knowledge sharing, and our opportunities to develop better solutions to problems.

The third major achievement was the establishment of the first democracy in ancient Athens. Several democratic institutions were invented, such 
as the Assembly of the People, the Council of 50o, and the People's Court. These institutions recruited a large numbers of citizens to engage in rapid and effective swarm problem solving. New decision-making methods were taken in use, such as majority rule and ostracism. The institutions also brought strangers together from all over the Athenian territory, and transformed them into their new role as citizens. This chapter argues that this direct democracy was built around a multitude of swarm mechanisms that became formalized for the first time. It led to the creation of a unique society, which was extraordinary successful, both culturally and economically.

\subsection{The Emergence of Group Hunting}

Obviously, humans have gradually become more able to solve problems together in larger groups. On this evolutionary path, group hunting is an important achievement that not only resulted in effective hunting, but also made it possible to live together in larger groups. For hundreds of thousands of years, humans only hunted smaller creatures and gathered food. They ate the carrion left behind by other carnivores and used stone tools to crack open bones in order to get to the marrow. As human groups increased in size to dozens, so did the demand for food. Small game would not be enough, making it vital to learn to hunt large animals, like bison, horses, and mammoths. A large food supply would save the group a lot of time and energy, but hunting large animals alone is both more difficult and more dangerous. In contrast, group hunting is easier and more effective. The human bands who mastered this skill would have had an advantage in evolution, also because they improved their general abilities to collaborate with each other. Hunting of large game would have required a plan and a hunting strategy, indicating collective problem solving that requires some degree of higher order cognition. At some point in time, humans managed to develop more advanced hunting tools and moved to the top of the food chain and began to hunt its predators instead of being hunted (Harari, 20I4; (Holler, 20I7)).

Recent research suggest that planned group hunting may have occurred much earlier than previously thought. The findings from a site on the shore of the lake at Schöningen show evidence of planned group hunting of wild horses among hominins about 300,000 BP. Horses regularly return to known predictable water resources and lakeshores are often used to ambush prey drinking at the waterline (Conard et al., 2015; Voormolen, 2008). However, it is both difficult and dangerous to hunt horses on foot 
because they are strong and fast moving. Nor is it easy to kill a horse with spears. If the horse is wounded, it is still mobile and even more dangerous. The hominins probably used an ambushing and stalking approach. If the horses were surprised, it would have been possible to drive the animals into the wet soft lakeshore zone to reduce their mobility and minimize the risk of horse defense injuries. This would have made it much easier to kill the horses by throwing multiple spears or stabbing at close distance. Some researchers even claim that a dozen or more animals were killed at the same time, requiring highly coordinated attacks (Conard et al., 2015; Voormolen, 2008).

The hunting behavior clearly demonstrates a high degree of planning depth, in combination with the use of deadly weaponry. The spears and the throwing stick had to be made well in advance of the execution of the hunts. The preferred raw material for making hard and strong spears was slow-growing spruce that grew under dry or otherwise unfavorable conditions. To make these wooden hunting tools requires planning, since it takes several hours to make a spear and the spruce trees are not found in the near-lakeshore environment. These tools were not made on the spot because of an immediate need. It suggests that the hominins were able to communicate about contexts beyond the here and now. It is likely that their hunting behavior required some type of language skills, since they were able to communicate about context beyond the here and now, talking about the past and the future, and about the spatial relationships in the environment. The spears are curated gear that were perfected through experimentation, optimization, and possibly exchange of information within and between generations. The use of these wooden artifacts demonstrates a high degree of planning, shared goals, and coordinated collective action. It shows that both Homo heidelbergensis and Neanderthals showed much more than purportedly primitive behavior (Conard et al., 2015).

These hominins used a range of sophisticated artifacts, were at the top of the food chain, exhibited a high level of planning depth, and coordinated behavior in their successful hunting. There is evidence that they repeatedly executed well-coordinated and successful group activities that likely resulted in new types of division of labor. For example, after the animals were dispatched, hominins systematically butchered the horses. Since a single horse can weigh as much as $550 \mathrm{~kg}$, the amount of food would far exceed the needs of an individual hominin. The butchering process also indicates that the food was shared between the members in a group (Conard et al., 2015). 
The findings from Schöningen indicate that human language developed gradually over the course of human evolution. Unambiguous evidence for fully modern language with fully developed symbolic and syntactical communication appears not before around 50,000 years ago. Nor is there any reason to assume that this evolution was uniformly gradual (Conard et al., 2015). Obviously, the cognitive level of hominins around 300,000 $\mathrm{BC}$ was obviously limited. However, if we look at how animal groups hunt together, it is plausible that human group hunting emerged as a mix of environmental sensing and primitive levels of higher order cognition. Like other carnivores, the human hunters may have followed simple behavioral rules in combination with some level of gestural communication, perhaps also verbal communication. As mentioned in the previous chapter, chimpanzees can perform advanced group hunting behavior just by following a few simple interactional rules. It is likely that human group hunters also utilized similar behavioral rules when surrounding the prey. Gestural communication could have been used to support coordinated collective movements and the production of hunting tools in more effective ways (e.g., using spears). These hominins were able to adapt and refine their hunting techniques in the specific local environment along the lakeshore and utilize the power of working together in increasingly large groups.

Certain evidence of advanced planned group hunting of large game can first be identified much later in human history. At one site in North America, a Columbian Mammoth was killed Io,000 years ago with eight different spear tips, found lying near the skull, ribcage, and shoulder. It shows humans hunted together, probably by throwing many spears at the same time while keeping a safe distance to the animal. It is likely that a human group could exhaust the injured mammoth by following it across long distances (Haury, Antevs, \& Lance, 1953). Two Russian sites, dated to around 21,000 BP and $13,500 \mathrm{BP}$, also show direct evidence for mammoth hunting. At one of the sites, the projectile was thrown from within five meters of the animal, so the mammoth was killed at close range. Because the size of African elephants and mammoths are similar, it is plausible that prehistoric hunters used the same hunting techniques as recent hunters who also kill elephants through group hunting (Germonpré, Sablin, Khlopachev, \& Grigorieva, 2008). In addition, the butchering process would probably have required teamwork. Experimental studies in which individuals have butchered an elephant with prehistoric tools show that the processing of skinning, meat removal, and dismemberment took 8-35 persons 2-Io hours (Germonpré et al., 2008). 
Most researchers agree that mass hunting among humans was not purely instinctive, as with the group hunting of carnivores, but it required higher order cognition (Nitecki \& Nitecki, I987: 3-6). When hunting large animals, it is more effective to be in larger groups and coordinate the attacks. In addition, it is an advantage to be able to communicate about different locations, map territories, and be able to use time and energy effectively when hunting. Here, linguistic skills are of help, but it appears to have evolved slowly over time (Holler, 20I7). With time, human groups developed more advanced hunting weapons and hunting techniques that made it possible to throw projectiles with more precision and accuracy (Holler, 2017). About 40,000 BP there was a major advancement in human hunting with the invention of new weapons and hunting techniques. These techniques were adapted to big game hunting like a battue, a driveline, and a surround. We know this from artwork that illustrate hunting in European caves, and it is also likely that the development of group hunting contributed to the prehistoric overkill, in the extinction of large mammals, the mammoth, mastodon, saber-toothed cat, and glyptodonts (Nitecki \& Nitecki, I987: 3-6). It illustrates that a new and more advanced type of collective problem solving does not necessarily result in a uniformly positive development.

\subsection{The Emergence of Premodern Trade}

Another important question in collective problem solving is when and how humans began to cooperate with each other across groups. In human evolution, most Paleolithic hunter-gatherers lived in small camping communities where their movements were shaped by the seasons and the migratory patterns of the wild animals, birds, and fish. However, these communities or human bands were not isolated from each other, but appear to have been directly connected with each other through both trade networks and periodic large gatherings (Gosch \& Stearns, 2007: 7-8).

From time to time, small groups of hunter-gathers would meet in large gatherings to renew friendships, to feast and dance, and to exchange information about animals and plants (e.g., like the powwows of Native Americans). Rituals and initiations were important, like the selection of marriage partners. Individuals or groups would also exchange various small objects (seashells, polished amber, carved wood or stone, etc.), which were both gift giving and trade. These exchanges are an important reason why one artistic style could spread across widely dispersed hunter-gatherer communities although the meetings only were occasional. The purpose 
of the large gatherings was not trade, but primarily to sustain social networks and symbolize the promise of mutual assistance (Gosch \& Stearns, 2007: 8; Smith, 2009: I3-14).

Second, it is also likely that premodern trade was an important antecedent to collective problem solving "between groups." It was organized as trade networks or down-the-line exchange, with a relay network that indirectly linked communities. For example, modern humans living in a cave in Tanzania I00,000 years ago had tools made of obsidian which can only be found 200 miles away, far beyond the normal foraging area of about 50 miles. It indicates that exchange network may have existed very early in human history. Another possibility is that the earliest trade occurred when hunting bands accidentally bumped into each other. However, dealing with strangers would be dangerous, so most exchange would take place between groups who lived close by and were connected to each other (Smith, 2009: I3).

Extensive premodern trade also coincides with expansion of Sapiens between 30,000 and 70,000 years ago. Within a remarkably short period, Sapiens reached Europe and East Asia. A range of important artifacts was invented like boats, oil lamps, bows, arrows, and needles. The first art artifacts appear, and there is evidence of religion, which suggest that humans are developing a new self-awareness (Harari, 2014). The most valuable artifacts were typically symbolic artifacts. Small sculptures of mature females, called Venus figurines, have been found over a huge area stretching from Western Europe to Siberia (Figure 5.I). Although, the tiny sculptures differ in many ways, they have enough similar features to suggest the spread of a common artistic style. It is highly unlikely that a group of travelers brought these figurines around; the wide distribution was probably made possible because of trade in a down-the-line system (Gosch \& Stearns, 2007: 7-8).

At sites in the middle of Europe, archaeologists have also found seashells from the Mediterranean and Atlantic coast at Sapiens sites that are 30,000 years old. These shells were probably part of long-distance trade between different Sapiens bands (Harari, 20I4). The Greek historian Herodotus tells an interesting story about something that was probably an amber artifact. A people called the Hyperboreans, who lived on the edge of the world, originally made this product. In honor of a long-established tradition, this group periodically, sent "sacred objects tied up inside a bundle of wheat straw" to their neighbors with orders to pass them on from tribe to tribe until they reached the Adriatic Sea. From there on, they were sent to Greece and ended up at the island sanctuary of Delos. It is interesting how 


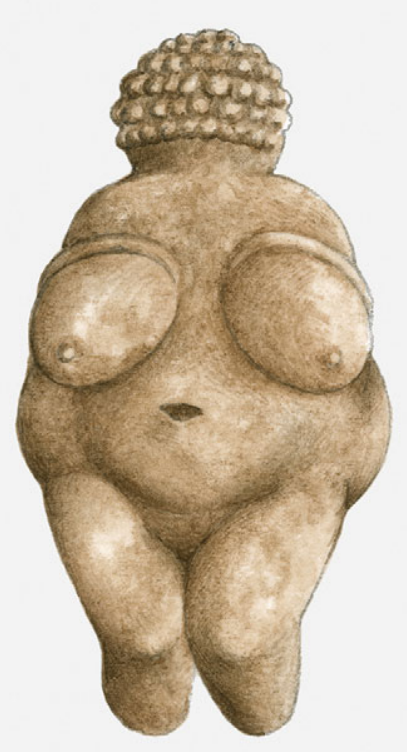

Figure 5.I The Venus of Willendorf. This is an I I-centimetre Venus figurine estimated to have been made around 25,000 years ago. It was found in Austria and is carved from a limestone that is not local to the area, photo Dorling Kindersley/Getty Images (C)

it was possible to transport such objects across such a long distance, with it being trustfully passed on through an unknown number of different people and places. The advantage with the down-the-line system was also that it did not require that anyone moved beyond their territory, which could be dangerous (Smith, 2009: I 5, 22).

In general, premodern trade did not involve goods that were necessary for everyday living, nor did it mean that one band was dependent on receiving goods from other bands. Items could have some practical uses, like the exchange of weapons. It was mainly about prestige items, artifacts of ritual or social value, like figurines or ocher for skin application. It could also include ornaments for personal decoration, like beads, necklaces, bracelets, and pendants made of bone, antler, animal teeth, shell, and stones (Smith, 2009: I4). The distance an object traveled was usually related to its value. Even a mundane object like certain kinds of flint or seashells could become valuable if they were transported hundreds of miles 
into territories where the objects were unknown. There, it would be perceived as exotic, and make the owner special (Smith, 2009: I4). Although the trade was not directly useful, it is likely that these groups at the same time also trade information, thus creating a denser and wider knowledge network.

Although these human groups did not necessarily move a lot outside their territory, premodern trade was still dependent on trusting people from other bands. Harari claims it is our ability to cooperate with strangers that has made us so successful in evolution, "Sapiens can cooperate in extremely flexible ways with countless numbers of strangers. That's why Sapiens rule the world, whereas ants eat our leftovers and chimps are locked up in zoos and research laboratories" (Harari, 20I4: 28). Perhaps the most important difference between humans and our nearest relatives, the chimpanzees, is that chimpanzees do not trust strangers or others outside their group.

It might not appear to be a big issue to collaborate with strangers, but early in human history this would have been very dangerous (Harari, 20I4: 29).

It is likely that trade was important in this human transition. It is a uniquely human activity that requires cooperation with strangers outside your own band, and it cannot exist without trust. Trust between strangers also became stronger when we began sharing some kind of common identity or shared belief in being similar to each other (Harari, 20I4: $38-40,52)$.

The human thrill of working with strangers is even evident in CI projects today. A solver in a virtual innovation team explain why he enjoys working with people from all over the world: "One of the things I really like about IdeaConnection is that you can meet people that you would have never met otherwise. So I've been on teams with people from Sweden, Switzerland, Mexico, USA, Canada, South Africa, Egypt and the UK and have made some enduring friendships, and some of these have led to other potential projects." The excitement is about meeting people that one would not have met otherwise. Here, the unknown other is someone who potentially can become a friend. What is interesting is also how fast people get to know each other through the intense work, as another top solver states: "I'm a people person so I like working with strangers. Out of the I 6 people I have worked with, I'm still friendly with I 5 of them. They don't remain as strangers after one week or so. That's a good part of working on the challenges." It is not unlikely that premodern trade had the same effect of establishing social networks between human 
bands who were neighbors to each other. With time, these systems enabled humans to share ideas and solve collective problems together in a much more effective way than previously.

\subsection{Human Swarm Problem Solving in Ancient Athens}

From 800 to $300 \mathrm{BC}$, Greece experienced a long and prosperous period, and the population became richer and more urbanized. In the period 508-322 BC, Athens is regarded as the most successful polis in Greece in terms of wealth, power, stability, and cultural influence. The outstanding achievements in this society were primarily driven by the establishment of the first large-scale democratic government in recorded human history. Reformed by Cleisthenes, this direct democracy let the citizens themselves govern society. Ancient Athens was a stable, prosperous democracy for roughly 200 years (Carugati, Hadfield, \& Weingast, 2015). This section argues that the new democratic institutions built on human swarm problem solving in their adoption of rapid decision-making in large groups. Four specific swarm mechanisms will be analyzed in more detail:

I. Maximizing information about the Athenian territory

2. Heterogeneous social interaction through rotation and lot

3. Decision threshold methods in the Assembly and the People's Court

4. Large gatherings in Athens

\subsection{Maximizing Information about the Athenian Territory}

An interesting characteristic with the Athenian democracy in the late sixth century BC is how it maximized information about the whole territory. Cleisthenes developed a new political system where adult males were given extensive rights to participate in the central institutions of polis government in Athens. He also reorganized the residents of the Athenian territory by intermixing the four traditional Ionian tribes and instead creating ten new artificial tribes. Each tribe was named after an Athenian mythical hero and would become a key marker of new Athenian identity (Ober, 2008).

The most important innovation in the new tribe system was to ensure that people from different geographic and economic zones would be a part of every tribe. Each tribe was divided into ten parts, with approximately one third being from the coastal, inland, and urbanized regions of Athenian territory. The new part of the tribe from the three different geographical sections were allocated by lot and each tribe was further 
divided into geographically based communities called demes, numbering a total of I 39 in the fourth century (Tridimas, 20 I I). For example, the village of Prasiai became one of the I I demes in the tribe of Pandionis, together with other towns, villages, or urban neighborhoods. Prasiai and three other nearby villages were the coastal demes of the tribe. In addition, there were four inland demes to the west, and three city demes - neighborhoods close to the city of Athens. As a result, all the villages from the same tribe would not be located in the same area and share a common border. The newly created tribes mixed a wide range of people in the Athenian population (Ober, 2008).

The new tribes would loosen up the existing strong-tie networks in villages and the traditional four tribes, and form a bridge between a stable local village identity ("resident of Prasiai") and the desired citizen identity ("participatory citizen of Athens"). The notion of citizenship was an important conceptual development, which implied that all locally born free men within a city-state had equal political rights and enjoyed legal protections, combined with obligations to serve the community (Carugati et al., 2015; Tridimas, 20 I I). Athenians from all over the territory would rule together, and participate together in psychologically powerful activities like fighting, sacrificing, eating, and dancing. Together, this new system strengthened the collective identity of the polis. This also made it easier to recruit soldiers to a national army that could effectively stand up against Sparta. In this time period, the Athenians were worried that the Spartans could destroy them (Ober, 2008). The members of a tribe would consist of all citizens from all over Attica and this new system helped forge a united army which had the immediate effect of defeating Sparta in 506 (Tridimas, 20I I).

If we look closer at the organizational design of the political system, the new tribe structure stands out as a key success factor. Good systems rely on many local bridges as the new tribal system aimed to create. Before Cleisthenes, the residents of Prasiai would have had relatively few bridging ties outside their local community, few connections with other towns or neighborhoods in Attica. This would limit the overall Athenian capacity for effective joint action like military operations. The tribe system established ties between groups that did not know each other from before, while retaining a sense of community at both a small and large level. In order to promote knowledge sharing, the basic requirement is to stimulate communication between people who in the beginning are strangers to one another and do not necessarily trust each other. The incentives were not necessarily only material, but equally important in establishing new relationships was the perception of being part of a new common culture and 
collective identity. In the tribe, groups came to know each other who would never otherwise have had contact. People with different backgrounds and knowledge would more frequently work together with people. The geographical representation in each tribe aimed to maximize diverse information about the Athenian territory, by including groups from coastal, inland, and urbanized parts (Ober, 2008).

In addition, it was necessary to create a meeting place for the new tribes if they were to get to know each other and share their knowledge with each other. To solve this challenge, Cleisthenes established the Council of 500 ("boule") in 507 BC, a new and remarkable institution of Athenian democracy. The Council prepared the agenda for the Assembly and had responsibility for the day-to-day administration of state affairs, supervising the state's finances, the fleet, cavalry, sacred matters like collecting tribute, construction work and care for invalids and orphans. They also monitored various projects that had been approved by the Assembly. The Council also met foreign delegations and reviewed the performance of the magistrates who worked in the government. This was done to avoid corruption and misuse of power (Ober, 2008; Wallace, 2013).

While all important matters of state policy, including finance and matters of diplomacy, war, and peace were decided in the Assembly of Athenian citizens, the Council had the important agenda-setting function by deciding what matters should be discussed in the Assembly. It was private citizens who brought issues for discussion to the Council. The Council would then consider if they wanted to bring the issue to the Assembly, for ratification of a specific decree. The Assembly, which any citizen could attend, was often chaotic because thousands of citizens were present. In addition, they had only 40 meetings per year, while the Council met daily and could therefore act more expeditiously than the Assembly (Ober, 2008; Tridimas, 20 I I).

Furthermore, the 500 persons in the Council comprised ten 50-man delegations from each of the newly created tribes. The members of each tribal delegation were selected by the demes and served in Athens for a one-year period. The number of councilors from each deme varied, depending on population in the deme. For example, the deme Prasiai annually sent three councilors as part of the tribe Pandionis' 50-man delegation to Athens. In contrast, one large inland deme sent I I councilors, while a small deme only sent one person (Ober, 2008). It illustrates that the system built on demographic representation.

The Council met every day except certain holidays, eventually in a purpose-built architectural complex in Athens. In a normal year of 354 
days, the Council met on about 275 of them (Hansen, I99I: 25I). Because of the intensity of the work, the tribal teams would get to know each other well during the one-year period they served. All the duties and collective work that were required would have stimulated rapid social tie formation, and made it easier to form new friendships with strangers. Every tribe would also work together with the other 450 councilors from the nine other tribes. Over the course of the year, members in the different tribes would become acquainted and likely establish weak ties in a new and extended social network. By establishing contact with men from other demes, one could hope to advance the family's position by seeking good marriages for his sons and daughters (Ober, 2008).

Nearly all members of the Council were ordinary citizens with limited administrative experience. A new group of 500 would join into service every year. Although councilors could serve twice in their lifetime, though not in successive years, it is likely that this did not happen often. It is likely that approximately 400 members were new to the Council (Hansen, I99I: 249). Consequently, no subgroup of old councilors could control the agenda in the Council, and all new councilors began on equal terms. They would quickly have to learn and acquire appropriate skills. Since all councilors were new in the job, this facilitated rapid knowledge sharing because it was important to get the government "running" as fast as possible. There was also a formal archival system, and many of the work routines for accomplishing the Council's work were codified. This must have been an important part of the knowledge sharing (see also Section 7.2). However, the regular turnover of councilors ensured constant innovation in the system as new people would bring in new perspectives every year (Ober, 2008).

Because the tribal teams served together in Athens for a whole year, it is likely that a lot of knowledge sharing between individuals would happen by itself. A councilor from a coastal deme might learn new pottery skills from someone in the city or how to improve olive farming from a councilor from the inland. The cost of communication is very low because all the councilors lived and worked together every day. The egalitarian structure of the Council would also have made it easy to bring forward relevant information to the right place, at the right time as a part of the collective problem-solving process (Ober, 2008).

The weak social ties connected individuals across regions, kinship groups, occupational groups, and social classes across the Athenian territory. Knowledge sharing was also promoted through state sponsored "knowledge aggregation contests" with public honors to the winners. 
The winners had to be capable of persuading others to do likewise. By creating an "economy of esteem," knowledge sharing was considered valuable throughout the community (Ober, 2008). For example, the work of the councilors was evaluated according to how well they had served the public purposes of the polis, and it could be rewarded at the end of the one-year period. The evaluation also reduced corruption or the risk of the Council developing into a self-serving identity (Ober, 2008).

Through its day-to-day operations, the Council sought to identify and make effective use of experts in many different knowledge domains. The councilors would also work in a range of different collegial boards that oversaw many of the administrative duties, typically composed of ten citizens. These teams were dedicated towards specific public tasks in the government like leading armies or keeping oversight of public festivals. In this way, the councilors would develop a certain expertise while still staying together with all the other councilors and sharing this knowledge (see more information about collegial boards in Section 9.3.2) (Ober, 2008).

The Council also played an important role because of its deliberative functions in the system. They would know who had a certain expertise and whom to contact to get relevant information. Each councilor would also have a network of contacts in the local home area. The Council would therefore easily have access to a significant amount of the total knowledge available in the entire Athenian population. In this new system, the Athenian population developed an increased capacity to discriminate among sources of expertise and information, and to cross-appropriate relevant knowledge from different domains (Ober, 2008).

\subsubsection{Heterogeneous Social Interaction through Rotation and Randomization}

In the last chapter, we looked at how heterogeneous social interaction is an important mechanism in human swarm problem solving. This section will investigate how heterogeneous social interaction first became part of an intentional institutional design in an attempt to solve different societal problems.

Several of the most important democratic institutions in ancient Athens used both random sampling and rotation to ensure that many citizens were allowed to participate. Every year this included 6,000 members to the Court, 500 members to the Council, and another 700 magistrates who served as public officers. Even though only the citizens who volunteered 
were part of the lottery, this lottocracy was an essential part of the democracy. When selecting candidates to the Council, there were assembly meeting in all 139 demes in the Athenian territory. For example, a deme entitled to four seats had to present at least eight persons. Some demes used lot in the selection of candidates, while others would struggle to get enough candidates. These candidates would then be part of a lottery in Athens that decided who would be the councilor and who would be the stand-in (Hansen, I991: 248; López-Rabatel, 2019).

Another interesting characteristic is the different rotation methods that were used to ensure shared responsibility in the Council. Each 50-man tribal team would take a leading role in directing the Council's business for a tenth of the year (36-37 days). In the Council, there was a monthly lottery regarding which tribe was to exercise the presidency of the Council. Every day, a new member from the tribe was also chosen by lot to serve as the chief executive officer or president of Athens. Every day at sunset, a new person would be appointed chairman who had not yet held the post. The chairman counted as the head of the state of Athens, holding the seal of Athens and the keys of the treasuries. He received foreign messengers and envoys and presided over meetings of the Council and the Assembly. As with most other positions, it was only possible to hold it once in a lifetime. A majority of the members in the Council would therefore have held the most important formal position in Athens during the year. The rotation principles aimed to reduce the domination of factions. Another positive effect was that a very large number of Athenians served in the government, and became more politically competent (Hansen, I99I: 250; López-Rabatel, 2019; Ober, 2008; Wallace, 20I3).

Furthermore, any citizen could also become member of the "People's Court," including the poorer members of society. The main purpose was to optimize a good rotation among the jurors and to stop any attempts to bribe jurors. The jurors were selected by lot at the beginning of the year and become members of the panel of 6,00o citizens. Those selected then swore the Heliastic Oath, and could choose when they wanted to turn up for the daily court meetings. However, they had to be picked by lot on a given day to serve for that day. On a normal court day, the Athenians had to use $2,000-3,000$ men from the jury list to pick up by lot $\mathrm{I}, 500-2,000$ jurors (Hansen, I99I: I8I-I89). The law courts selected thousands of citizens every court day through complex randomized procedures that guaranteed that jury panels were broadly representative of the Athenian population as a whole (Carugati et al., 2015). 
In the fifth century, the potential jurors formed a queue in the morning in front of the courtrooms and were let in according to the order of their arrival until the required number of jurors was reached. From the end of the fourth century, the jurors were selected by lot and also allocated to the different courts by lot. The courts were all placed in the corner of the Agora behind an enclosure, with one entrance per tribe. Court proceeding began at dawn with the selection by lot of the day's jurors from those of the eligible 6,000 who had met. In front of each of the ten entrances, there were ten chests. People met at their tribe entrance and put their jury plaques in the specific chest that displayed the same letter that corresponded to the one they had on the plaque (Hansen, I99I: I83, I97-I98).

When all potential jurors from one tribe had delivered their plaques, one person would be selected randomly from the ten chests to help organize the lottery with the help of a kleroterion (Figure 5.2). The Athenians invented this lottery machine to execute the lotteries in an effective and fair way. The machines were designed to guarantee equality between all participants in the lottery, avoid fraud and allow a faster and more complex way of drawing of lots. The kleroterion marks a decisive turning point in the evolution of political tools intended to serve the democratic ideal. It made the drawing of lots much more effective in the fifth and fourth centuries BC. Lotteries became more frequent, and included a larger group of citizens. For instance, in the People's Court, it was necessary to draw lots for thousands of jurors approximately 200 days a year (Hansen, I991: I98; López-Rabatel, 2019). ${ }^{\text {I }}$

These lottery machines were made of marble, were almost two meters, and would normally have five columns of slots corresponding to the size of a jury plaque. The lottery organizers picked identification plaques from the chest and inserted them into the kleroterion. One had to fill the columns with the section letter that appeared on the citizens' identification plaques (pinaikon) and identified the tribe. The kleroterion also had a narrow vertical tube, where they put a specific number of black and white balls that corresponded to how many jurors they needed. The balls were then removed from the bottom of the tube, one at a time. When the ball was white, the row of the five plaques were accepted as jurors; if they were black, they were rejected. Regardless of the size of the group that was to be selected, the number of columns of the machine would match the number of tribes. Two lottery machines were used to include representation from all the ten different tribes. The machine established a uniform procedure that ensured a fair lottery (Hansen, I991: 198; López-Rabatel, 2019). 




Figure 5.2 The kleroterion, the Greek lottery machine. These machines were primarily used to select jurors in Athens. Each court had machines placed in front of the entrance. The model of this kleroterion has I I columns and was probably not used in the courts, but in the Council. There were $\mathrm{I} 2$ tribes in the third century BC and the kleroterion could then be used to select committee members representing all tribes except the one holding the presidency, photo Gianni Dagli Orti/REX/Shutterstock editorial/NTB (C) 
After the selection of jurors, another selection by lot began that distributed them between courts. It varied whether the day was devoted to smaller private suits with $20 \mathrm{I}$ jurors or larger ones with $4 \mathrm{OI}$, or to public prosecutions with $50 \mathrm{I}$ or more. The most important political cases could include panels of I,OOI, I,5OI, 2,OOI, and 2,50I. Because the size of the jury was designed to increase with the seriousness of the case, this suggests that the Athenians had some awareness of a wisdom of the crowd effect. By increasing the size of the jury, it was assumed that this also increased the likelihood of reaching an accurate and fair decision (Hansen, I99I: I 87-188, I99).

Since the distribution of jurors between the courts was done by lot, it is likely that all courts were of the same size on a specific day, for example $20 \mathrm{I}$ or $50 \mathrm{I}$ individuals. On an ordinary day, there would be activities in at least three courts, and probably four or more. During the day, it would be possible to arrange at least three public prosecutions or at least $\mathrm{I} 2$ private suits. The whole lottery process might have lasted an hour involving more than 2,000 citizens, approximately 200 days a year (Hansen, I99I: I 87-I 88, I99).

The drawing of lots was an important part of the institutionalized practices in Athens. The machine could involve the entire citizen population through rigorously defined procedures. It seems to have taken a century after Cleisthenes reforms to invent a "democratic machine." Exposed to the sight of all, the kleroterion also guaranteed transparency and a fair procedure, with the lottery becoming part of the rituals of public life. It became a powerful symbol of the new political logic. It gave every citizen the same chance of being selected, and it made bribery very difficult. No one knew in advance who would be in the juries, nor what case they would judge. The voting equipment also underwent a gradual transformation towards standardized voting tokens with less emphasis on religious symbols. In the classical period, it appears that religious symbolism was not as dominant in the procedure of lottery (López-Rabatel, 2019) (Hansen, I991: 199).

Furthermore, most of the magistrates or public officials were selected by lot. They were appointed annually to different posts in public office, working on religious, judicial, or financial matters, as army and naval commanders or inspectors (of markets, building, roads, water, and country districts or in steering committees for the Assembly). Their power was limited because they could only serve one period in a specific area, except for the generals, who could be reelected. Still, a citizen was allowed to hold a different position at a later point of time. This system created frequent 
rotation and a large proportion of the citizens would therefore hold office eventually. The various magistrates were amateurs and there were very few professional administrators (Hansen, I991: 236, 243; Tridimas, 20 I I).

If we look closer at the lottocratic selection of magistrates, several advantages are apparent. First, the citizens have equal chance to serve in public office independent of the wealth, or ability to finance an election campaign. Because a large pool of candidates is randomly selected for a limited period, this resulted in a significant rotation in office, which increases the likelihood of getting the position. This creates a system that is perceived as fair. The frequent rotations ensures that every citizen will alternate between being governed and governing, which further reduces factionalism. Second, because the number of appointees is "large," the process of randomized selection will ensure the magistrates reflect proportionately the preferences of all citizens in the population. When the number of officials appointed in a board of magistrates is sufficiently large, the law of large numbers applies. Third, compared with elections, the lottocratic system is relatively easy to administer and produces outcomes more quickly. It reduces the economic costs of making collective decisions. Fourth, the lottocratic model prevents the development of a professional political class or an elite group that can gain too much power. There will be fewer interest groups which influence the system and less corruption. The benefits of holding office is spread widely across the citizenry and promotes equal opportunities for all citizens to occupy office. It also decreases the power of the office holder and the attractiveness of office; reducing conflicts among individuals over power and possibly discouraging corruption in seeking office. The system is perceived as fair since it provides citizens with equal opportunities to assume public office.

Fifth, the frequent rotation of citizens in various public posts as magistrates, councilors, or jurors must have significantly increased citizens' knowledge about the Athenian society. Knowledge was shared through participation between most of the citizens in various weak-tie networks. Although jurors could not discuss issues during the case, there must have been many discussions afterwards (Tridimas, 20II). Likewise, the councilors who worked together for a year would most certainly learn a lot about the polis and gain a deeper understanding of the democratic system and the larger governmental system. Gradually, a very large number of citizens in the entire Athenian territory would have acquired political expertise. Athenian performance also improved because more citizens gained political expertise and became part of the self-government system. This type of participatory democracy also creates a transparent 
governmental structure and was designed to strengthen support for the Athenian polis. The democratic institutions were refined and modified over time, but some of its original parts from the late sixth and early fifth centuries proved remarkably durable (Ober, 2008).

However, several of the democratic institutions had age restrictions. The Assembly was open for all Athenian males above 20 years, but all other institutions such as the People's Court, the public office (magistrates), and the Council required participants to be at least 30 years old. The system favored certain age groups. Since a juror in the People's Court had to be at least 30 years old, it limited the eligible candidates from thirty to twenty thousand citizens. In the Council of 500, the average age of first-time members was about 40 , so citizens did not become councilors when they had just turned 30 . The group over 40 years of age represented only 2 percent of all citizens. Consequently, about two thirds of all Athenian citizens over 40 would have been a councilor. Since 6,000 jurors were drawn every year, the numbers suggest that the average citizen above 30 would be juror every third year. The eldest and most experienced were considered better qualified in doing this work, indicating the presence of organized group differentiation. In addition, adults in their 20 s were needed for many other types of work in the society (Hansen, I99I: I 8 I, 249).

Moreover, one should be aware that there are potential disadvantages with rotation and random sampling. It is not possible to select the persons who are considered to be the most qualified to do work. If individuals know that they will be doing the work only for a limited time, such as a year, this might reduce their motivation. Since the model is based on volunteering, the recruitment may still not be good enough. The lottocratic appointment of public officials also requires that all citizens can learn the skills to do a sufficiently good job in a short time. The success of the system provides evidence that amateur officials were able to perform both simple and complicated duties. However, officers responsible for defense were appointed by election in Athens, which shows that some posts required expertise (Tridimas, 20II).

\subsubsection{Decision Threshold Methods in the Assembly and the People's Court}

In the previous chapter, both quorum responses and majority decisions were identified as essential decision threshold methods in human swarm problem solving. In this section, I examine how these methods were first taken in use in societal institutions. If we look back to ancient Athens, 
both the Assembly and the People's Court were organized around majority rule and also a few quorum rules. Simple majority rule became formalized as the preferred decision-making method in two of the core institutions in society. For the first time in human history, it became possible to aggregate opinions in mass audiences in a very effective way -6 , 000 citizens in the Assembly and 200-500 jurors in the courts. Both institutions made essential societal decisions under significant time constraints (Ober, 2008). The new voting methods symbolized the beginning of democracy, a radically different society, built upon a new type of individualism that ensured individual rights and equality of the votes (Pitsoulis, 20I I).

If we want to trace the first voting practices, we have to move even further back in time to the Spartan popular assembly around 750 BC. In making decisions, the supporters of conflicting proposals organized a "shouting contest." A couple of persons were locked up in a room nearby so they could not see nor be seen by the "shouters," but only hear the sound level of the shouting in the assembly. This impartial group then decided which candidate had received the loudest acclamations and could become a senator. We know less about the origins of majority rule in Athens, but it probably began with formal voting at the end of the seventh century. However, it was the democratic reforms by Cleisthenes in the fourth century that formalized majority rule as an essential decisionmaking method in the democratic Athenian constitution (Pitsoulis, 20I I).

It is likely that military practices led the Greeks to begin using majority rule. Because new weapons were invented, like the double-handled shield, battles were increasingly won through group formations. The hoplites emerged as a new group of free landowning citizen-soldiers in the sixth or seventh century. They became powerful because they could now defeat the aristocratic horsemen with their superior military strategy. The group of soldiers would move together in a phalanx, a rectangular mass military formation, and they would battle by pushing against each other until one broke (Figure 5.3).

Numerical superiority was decisive in these battles. There were numerous civil wars between hoplites in Greece, and it is from one of these that Xenophon reports that the battling parties found out that it was better idea to just count the number of soldiers instead of fighting, and then give the victory to the group with the most soldiers who would anyway win. Frequent warfare became very costly, and majority rule in the battlefield was a conflict resolution mechanism that would be beneficiary for both parties. The hoplites were also "middling men" who wanted more influence in the city states, and one way of achieving this was through majority rule. In the 


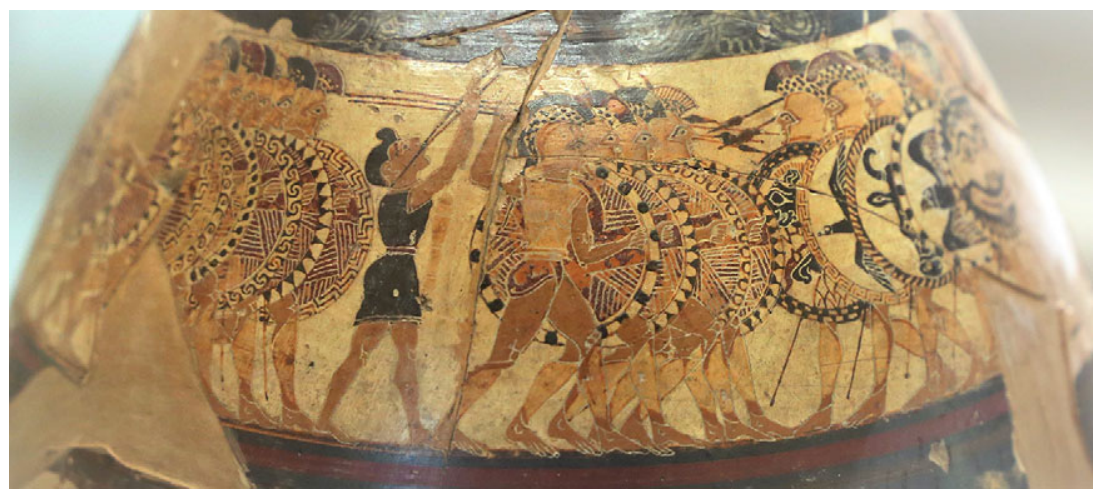

Figure 5.3 The Chigi vase from seventh century BC showing hoplites going to battle, photo Francesco Bino, image courtesy of The National Etruscan Museum (C)

Solonian Athens in the sixth century BC, only the hoplites had the right to vote and the privilege of being eligible for public office (Pitsoulis, 20 I I).

\section{Voting in the Assembly}

If we move a century forward to the Assembly in Athens during Chleistenes, we know more about the voting system. Citizens normally voted by show of hands in contrast to the People's Court who voted by ballot. The "ayes" were first called to raise their hands and then the "no's," with abstention also being an option. It is most likely that there was no exact counting of hands, a voting practice that is still used today in the Landsgemeinden in Switzerland. Because every vote counted equally, it is easy to get a visual estimate of the majority by just observing how many hands are raised. Since exact counting was unnecessary, this was an extremely time-efficient voting method. It was the nine chairmen of the assembly (proedroi) who estimated the majority, with the vote being repeated if they were in doubt. Therefore, the Assembly could make many decisions in just half a day. Six thousand citizens would normally be present at an Assembly meeting, which was the maximum number the meeting space, the Pnyx, could contain when it was full. This made voting easier when a quroum rule of 6,000 was required to vote, because one did not have to count the individuals who were present. Pay was also introduced to motivate attendance, being much more lucrative than in the courts. It was more difficult to get one fifth of the citizen population to turn up regularly compared with the courts, which required less attendance (Hansen, I991). 




Figure 5.4 Ostraka, shards of pottery used as a voting ballot. The name of Themistocles, son of Neocles, are written on the shards of pottery. He was banned from Athens through ostracism in 470 BC, Agora Museum, Athens, Greece, photo Akg-images/NTB (C)

Furthermore, Cleisthenes invented ostracism, a unique voting method that aimed to pinpoint the person who posed the largest threat towards the society. The individual who "won" this vote, usually a political figure, was banned from Athens for ten years. However, this was not an ordinary penalty, because the person did not lose status or property, and could access his fortune from abroad. Once a year, the Assembly voted by a show of hands whether they wished to hold an ostracism. If the majority answered yes, a special sort of "election" was to be held in the Agora two months later. Each citizen was expected to make up his mind, and there was no publicly available information. In the final vote, any citizen wrote the name of a person who they thought should be banished on a pottery sherd (ostrakon) (Figure 5.4). A quorum rule was used in the voting. If there were more than 6 ,000 votes, the person with the highest number, who received a plurality of votes, was exiled (Hansen, I99I; Ober, 2008; Tridimas, 201 I).

The characteristics in ostracism are exceptional. Although a person was exiled, there was no legal trial because no charges were filed. There were no 
public speeches of prosecution or defense from the expelled person in the Assembly. The logic in the procedure was the opposite of a trial; citizens were first asked whether they wanted someone to be guilty and they would then have to select this person afterwards. The invitation to ostracism was performed every year and did not require any initiative. This voting method can be interpreted as a type of prediction vote on which person is most likely to cause the greatest harm to the city in the near future. By aggregating the opinions from all citizens, one can prevent this from happening. However, one could only expel one person, but others who had been close to being expelled might also have felt a pressure to improve their behavior. In the two months before the vote, ordinary citizens must have felt some degree of power over the most privileged groups in society. While we don't know if ostracism had an overall positive effect, it was used I 5 times during the fifth century and quite frequently in Athens' most successful period (480s-440s BC) (Hansen, I99I; Ober, 2008; Tridimas, 20II).

\section{Voting in the People's Court}

If we look to the voting method in the People's Court in Athens, it was built on simple majority rule, but still it was quite different from the assembly. The group of voters was much smaller than in the Assembly, although it was still very large compared with modern standards.

Jurors would never be below $20 \mathrm{I}$ jurors, and groups of $4 \mathrm{OI}$ or $5 \mathrm{OI}$ jurors were most common. However, in a few very important public cases, several thousand jurors were invited. The procedure was organized in such a way that the jurors first listened to speeches from both parties, the prosecutor and the defender. Then there was a vote by secret ballot, not by hand like in the Assembly. Jurors were not allowed to deliberate on the case before the casting of the votes. The jurors were given two different bronze voting-disks, one that supported the defendant and the plaintiff or prosecutor. The valid votes were then cast into a bronze urn, while the others were put in an urn of wood. To avoid cheating and ensure secrecy, the urns were covered in such a way that they only allowed one vote at a time. The verdict was made in favor of one of the two litigants by simple majority rule, and the decision was final. There was usually no risk for a private prosecutor if he lost his case, but in certain cases, he would have to pay a fine of one sixth of the sum at issue. If the prosecutor in a public case received less than a fifth of the jury's votes, he received a fine of I, ooo drachmas and lost some of his citizen rights. These rules were designed to reduce the frequency of political prosecutions, which potentially could 
"overheat" the court system (Carugati et al., 2015; Hansen, I991: I92, I99, 202, 218).

This second round of deciding the penalty followed the same anonymous voting procedures. In most cases, the two involved parties proposed one penalty each. After the first vote was finished, both parties held a new short speech where they argued for the proposed penalty. The jurors were required to select one of these two options, and they could not propose their own penalty. This made the penalty decision very time efficient. If a party, also the defender, wanted to win a majority vote, he would have to propose a reasonable penalty that could stand a chance of winning the vote (Hansen, I99I: 202). In the legendary trial against Socrates, scholars have claimed that he invited his own death by first joking and arguing he should be rewarded and not punished. Eventually, he proposed a very small fine ("Socrates was guilty as charged," 2009). The jury found Socrates guilty by a vote of 280-220, which suggests that he probably would have avoided the death penalty if he had not joked and proposed a higher fine (Linder, 2002).

The most common explanation of why the jurors were not allowed to discuss the cases with each other, was to avoid corruption. Since the courts were set on the same day and decisions were made the same day, it was very difficult to bribe the jurors. If one examines the voting method in a swarm perspective, it is strikingly similar to a traditional wisdom of crowd approach (Surowiecki, 2005). Quality decisions were ensured through large group size, representative jury panels, majority voting with binary options, and independent judgments. Independent judgment was highlighted in several different ways. The jurors had sworn the Heliastic oath, they made secret votes, and were not allowed to discuss issues with each other. Because the jury would never be less than $20 \mathrm{I}$ independent decisions, it appears that the system unknowingly utilized advantages of the law of large numbers. Large groups increased the probability of reaching a correct verdict when individual opinions were unbiased. The jury system also adhered to this logic by increasing the jury size even further in the most important cases. In addition, the lottocratic selection of jurors ensured a randomized representation. The median juror had preferences close to the normative expectations of the median member of the Athenian community. Therefore, the litigants would need to take into account the existing "citizen spirit" when arguing for their views in the court (Carugati, $2015)$.

The People's Court system builds on a trade-off between accuracy vs. speed, a typical characteristic in human swarm problem solving. Athenians 
definitely emphasized decision speed, as court decisions were made within a day. This is much less time than what is common in courts today and suggests a significant risk of making bad decisions. However, one could argue that these rapid decisions were compensated by increasing the jury group size, which was much larger than a normal jury size today. Most citizens must have acknowledged the jury system as a legitimate decisionmaking method, as even Socrates accepted his verdict, claiming, "He owed it to the city under whose laws he had been raised to honor those laws to the letter" ("Socrates was guilty as charged," 2009).

\subsubsection{Large Gatherings in Athens}

In ancient Athens, all democratic institutions can be regarded as large gatherings of people coming together to solve problems. This swarm component includes the Council of 500, but also the Assembly and the Court, which involved a large number of citizens, but for a much shorter period.

\section{The Assembly Meetings}

In Ancient Greece, the Assembly in Athens was particularly important. In $594 \mathrm{BC}$, nearly all adult male Athenian citizens were allowed to participate in the Assembly at the age of 20 after they had completed their military service. Excluded were woman, metics, slaves, and citizens who had lost their rights. Still, this allowed the poor group of citizens to become the new majority. Meetings of the Assembly were normally held on the Pnyx, a low hill about $400 \mathrm{~m}$ southwest of the Agora (Figure 5.5). In the fifth century, the people sat in a semicircle directly on the rocky surface, and on the north side, there was a low wall that must have been the place of the speakers' platform. The area was about 2400 square meters and the elevation sloped from south to north. The Pnyx was almost a symbol for the Assembly, and even for the democracy itself. Very few other cities had an independent Assembly place, and most used the Agora or the theatre (Hansen, I99I: I27-I 29).

The Assembly was always summoned by the executive group (prytaneis) in the Council of 500. It originally met ten times a year, but it gradually increased to 40 meetings a year. The meeting could not be held on festival days, "taboo-days" or when the People's Court had juror meetings. The Council normally set the agenda on their own initiative, and it was typically published four days in advance. In this way, citizens had some time to discuss issues prior to the meeting. Normally, at least nine items 


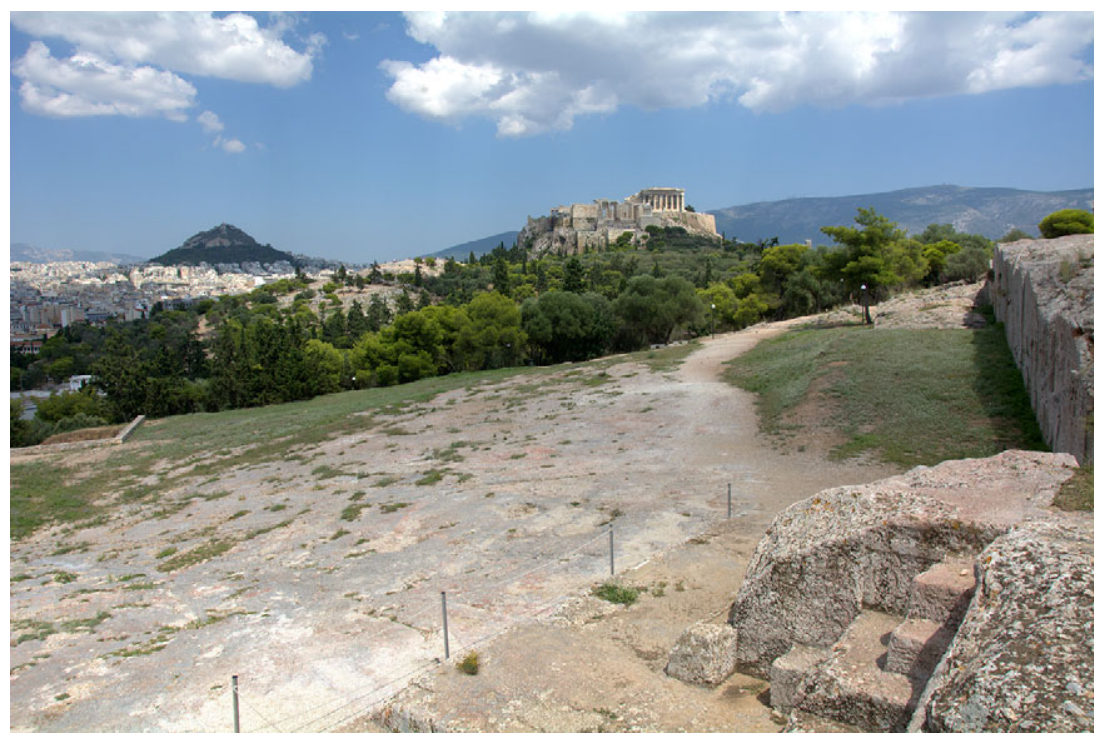

Figure 5.5 The Pnyx hill in Athens where the Assembly had its meetings, photo Miguel Sotomayor/Getty Images (C)

would be on the day's agenda, but the meeting would last only half a day, so the pay was full compensation for ordinary hours of work. The Assembly was most important in relation to foreign policy. Diplomacy was important, illustrated by how both Phillip of Macedon and Alexander the Great were made Athenian citizens. The Assembly also rewarded deserving foreigners, metics, and citizens. A large number of decrees were ratified, such as citizenship grants and honorary decrees or those related to foreign and military policy. Often, the ratifications were simple and uncontroversial and they would pass without debate, as is often the case in the Swiss Landsgemeinde today (Hansen, I991: I33-I 57).

In the Assembly of 6,000 people, deliberation or extensive discussions were not possible. The debate would therefore consist of a series of speeches of varied length. It varied whether the speeches were prepared or not prepared (also with or without a text). Communication was only one-way, from speaker to audience. According to the law, there was to be no communication from audience to speaker. Nor were there to be any communication between speakers, but one could obviously refer to previous speeches. However, at every meeting the audience interrupted with applause, protests, or laughter. Heckling from the auditorium was often 
unrehearsed, with questions requiring clarification and some dialogue between the speaker and members of the audience. Still, the vast majority of the audience of 6,000 would listen and vote on the motion without discussion. Although only a tiny minority were active in the Assembly, the democracy would still very much depend on the active contributions from this group. Honorary decrees and prizes like gold crowns were even awarded to the best rethor of the year in the Assembly or the best executive group of 50 from the Council (prytaneis). "Rhetoric, or the 'art of persuasion' was considered to be important when individuals presented an issue" (Hansen, I991: I42-1 57).

\section{The Court Meetings}

Another important large gathering was the People's Court, which met approximately 200 days a year. The Court was a separate and independent institution from the Assembly. In the classical period, the Court tried both civil and penal cases, but the most important function was political control of the other institutions. It organized prosecutions against public officials and helped prevent misconduct or abuse by office holders. Although formal written law existed, and the court was regulated by written legal procedures, the system was dependent on the voluntary efforts of citizens at large. Prosecutions relied primarily on private initiative and citizens had to "present their case" without any lawyers. There was no public prosecutor who brought a charge. All the judges were also citizen-amateurs, and an amazingly large number of citizens took an active part in the law, not only as jurors but also as prosecutors or plaintiffs. Originally, only the injured party had the right to bring a case. A citizen would have to learn how the system worked because it was forbidden by law to pay another citizen to appear as your advocate in court. If the jury permitted, one could share speaking time with a friend or relative, and in political trials there were usually several speakers from the same group. One could also get help from a professional speechwriter although this profession was regarded with skepticism and suspicion (Carugati et al., 2015; Hansen, I99I: I89, I9I, I94; Tridimas, 201 I).

The judges volunteered by choosing which days they wanted to turn up for the daily court meetings (Hansen, I99I: I8I). The court meeting followed specific procedures. A public prosecution took the whole day, lasting nine and a half hours. The accuser and the accused had about three hours for their speech. The remaining three hours were needed to select jurors, read the charge, vote, and arrange new speeches for meting out punishment, a further vote on the punishment, and so forth. In private 
suits, the time for speeches varied according to the value of the suit: suits for over 500 drachmas got the longest time and could perhaps last more than two hours, while suits for less than Ioo drachmas could perhaps be heard in less than an hour (Hansen, I99I: I 87). The hearing began with the reading aloud of the written charge and the reply of the defendant. The plaintiff or accuser would begin their speeches and then the defendant. In a public prosecution, each party made only one speech, but it could last up to three hours. In a private suit, the time could at most be about forty minutes. In these cases, the parties were both given a chance to meet each other's point in a short reply and reply-to-reply (Hansen, I99I: I 87, 200).

Since the cases were allocated by lot in the morning, the jurors would have few opportunities to discuss the cases in advance. However, for the Athenians, the purpose with the large number of jurors was to counterpose those who are so rich that they could buy followers (Hansen, I99I: I 88). Compared to court trials today, these procedures are much shorter, and one can reasonably ask if they are too short because there is no time for juror deliberation. Although the rapid problem-solving time and the independent anonymous voting may have originally been motivated by an attempt to avoid corruption, this organizational design resembles the wisdom of crowd approach in several ways (Surowiecki, 2005). First, there is an emphasis on independent individual opinions, which is present in the fact that jurors had to swear the Heliastic Oath:

I will cast my vote in consonance with the laws and with the decrees passed by the Assembly and by the Council, but, if there is not law, in consonance with my sense of what is most just, without favor or enmity. I will vote only on the matters raised in the charge, and I will listen impartially to accusers and defenders alike (Hansen, I991: 182).

Both the emphasis on individual assessment of what is "most just" and the ability to "listen impartially" resembles the original focus on independent opinions as a basic characteristic in a wisdom of crowd approach (see Section 4.I). Jurors were to make up their own opinion without discussing the issue with other jurors during the court meeting. Because jurors were selected every day, new people would sit together every day, which made it difficult to establish informal subgroups. The phrase "without favor or enmity" in the oath also shows how social influence is perceived as a potentially negative factor. Because voting was anonymous, the oath might seem like an empty formality, but jurors feared divine punishment. Therefore, a decision made by sworn jurors was considered more important than decisions in the Assembly where participants did not swear any oath (Hansen, I991: I83). 
Second, the involvement of a large group of jurors was assumed to improve the collective problem-solving process. Even the smallest group of $20 \mathrm{I}$ jurors is large enough to benefit from the law of large numbers and the many wrongs principle. By having a large number of jurors, the Athenians minimized the case time and still hoped to reach accurate decisions. Although the Athenians increased the meeting time in important cases, the compensation for a rapid process was primarily to increase the jury group size.

\section{Swarm Mechanisms in the Assembly and the People's Court}

Being a large gathering that solve problems, both the Assembly and the Court utilize several swarm mechanisms. Both resemble swarm problem solving in how problems are predefined before the meeting. Both institutions are not least highly effective in their emphasis on rapid problem solving. Both the Court and the Assembly had to make decisions within the limits of one day's work. Every Athenian jury had to arrive at its judgment by day's end, even when there were several cases per day. While the time schedule in the Court was strictly regulated, the Assembly had a bit more flexibility. Still, most meetings would only take half a day, but it could be extended to the whole day if deemed necessary. However, the work in the Assembly was more unreliable since it was done outdoors in comparison with the Court where work was done under roof (Hansen, I99I: I9I).

If we compare the opportunity for deliberation in the Court with the Assembly, we see that the Assembly permitted some degree of deliberation prior to the meeting since the agenda was published a few days in advance. In contrast, the jurors had no opportunity to discuss issues in advance, since the cases were decided the day they met. In both meetings, rhetoric was important, as speakers or litigants would provide the only information to the large group before they voted. However, the Court allowed for significantly more time to the present multiple viewpoints. Speakers addressed complex matters by advocating different and mutually incompatible courses of action (Ober, 2008).

\subsection{A Summary of Human Swarm Evolution}

In this brief history of the origins of human swarm problem solving, we see how the ancient democracy in Athens emerges as part of a gradual evolution in human history, from minimal stranger interaction, to informal stranger interaction in premodern trade, and eventually to formalized 
patters of stranger interaction through democratic institutions. Ober (2008) claims that the key success factor in the Athenian democracy was how strangers were transformed into citizens who were connected to each other in "weak-tie" networks. In contrast to strong social ties, weak ties (e.g., when my friends are unlikely to be friends with one another) promote more effective sharing of information across the whole organization and it ensures cohesion. Small-scale networks with strong ties are usually very good at internal knowledge sharing, but they are poor at knowledge transfer to the whole network. However, the time dimension of large gatherings is important to consider. For instance, the Council of 500 shows that part of the success was due to giving individuals enough time to get to know each other, and then afterwards bring this knowledge back to their local deme. It institutionalized heterogeneous social interaction and established a knowledge-sharing culture across diverse groups of people in the polis who had been strangers to each other. Therefore, the Council became a meeting place that increased the likelihood of sharing best practices or new inventions in the territory.

One could claim that interaction between strangers is at the core of human swarm problem solving because it enables collective problem solving in much larger groups. In the online setting today, the ability to trust unknown others is also one of main challenges in designing successful CI. A top solver in a virtual innovation teams illustrate how this can also be an exciting experience:

I have met people with varied interests, and we all like to step out of our little box that we are employed in. And you find that people regardless of their culture or the country they live in are all pretty much the same. It has been a mindopening experience that has allowed me to go into areas I would never have been able to do before without going and getting a master's in something or some other college degree. I have learned a lot of things (s.57).

Through collective work, the solver discovers how people actually are "pretty much the same," echoing the entire Athenian system that was designed to bring strangers together. The Athenians also had to "step out of their little box" and engage with other strangers. In this final section of the chapter, the origins of swarm problem solving will be summarized through the description of two subtypes of swarm problem solving. On one hand, pinpointed swarm problem solving refers to an attempt to find the one exceptional solution that stands out compared with other proposed solutions. In synchronized swarm problem solving, the solution lies in combining all the different contributions. Both types of problem solving predefine a problem and solve the problems according to a set of 
predefined interaction rules. The tasks and roles are also defined in advance, but the value of human diversity is utilized in different ways. Pinpointed swarm problem solving seeks one or a few winner solutions from some of the contributors, while synchronized swarm problem solving includes all contributions as a part of the winner solution.

\subsection{The Evolution of Synchronized Swarm Problem Solving}

As the historical examples in this chapter illustrate, the story about ourselves is very much a story about our ability to solve problems in increasingly larger groups. Swarm problem solving emerged as a new type of collective problem solving, different from collaborative problem solving, in its ability to solve problem with a minimum of deliberation.

Group hunting represented a breakthrough in how humans could more effectively acquire food by working together in large groups. Like with group hunting among other carnivores, it is essential to coordinate actions through simple behavioral rules that all individuals follow during the hunt. The hunt would build on synchronization in the sense that every contribution from individual hunters matters and is equally relevant. The actual group hunting consists of synchronized movements, which involve contributions from everyone. The rapid synchronization is built around simple behavioral rules. Each hunter will observe the actions of other "near-neighbor" hunters, and the collective action can be regarded as a navigational problem that requires synchronization of dependent contributions. This type of swarm problem solving can perhaps best be described as group sensitivity and resembles the performance of a sports team where each member responds to the behavior of the entire group. It is different from rule-orientated collaborative problem solving in its emphasis on embodied cognition and indirect coordination.

Early hominins would probably have used similar interactional rules, but there is also evidence that they could effectively plan the hunt in a specific environment, which would at least have required advanced forms of gestural communication. Each group had a shared understanding of the challenge, and that a successful output was dependent on contributions from everyone, during the preparations, the actual hunt, and the butchering. The outcome of the group effort would also be much more valuable than what a single hunter could achieve on his own.

The invention of voting systems in ancient Athens represents the historical development of a more advanced type of synchronization. The benefits of large groups had become more prominent in warfare with 
the hoplites, and majority voting attempted to use a similar mechanism in governing societies. Majority rule allow everyone to be part of a decisionmaking process by taking a stance on simple "yes" or "no" alternatives. An important advantage is the speed of collective decision and the clarity of outcome.

Methods that built on "numerical decisions" made it possible to involve a large group of people in time-efficient decision-making. In a historical perspective, it became increasingly difficult for larger groups of people to coordinate collective work when they settled in towns as they grew in size. Different voting methods made it possible to synchronize information from many individuals by effectively aggregating the opinions of increasingly large groups. A vote also represented an equal contribution from every individual. This was both practical and it strengthened the idea of all citizens being equal. The kleroterion, the lottery machine, is an interesting example of a technology that ensured fair and equal representation from all the different tribes in Athens.

Furthermore, the court system in Athens synchronized individual contributions in ways that resemble a "wisdom of crowd" approach. Sortition ensured diverse representation and frequent rotations of participations reduced misuse. Oaths and anonymous voting ensured independent opinions. The prohibition against discussions between jurors illustrates the dedication towards individually independent judgments. All jury groups were very large, with a minimum size of $20 \mathrm{I}$, and even larger in the most important legal cases. This shows the presence of the idea that if many individuals vote, more accurate and fair decisions can be made.

Human swarm problem solving gradually evolved into more complex types of synchronization, beginning with dependent contributions in group hunting and then later being transformed into formalized voting systems that synchronized independent contributions. Today, the digitization of numerical data make it possible to utilize synchronized swarm problem solving in new ways. The online setting makes it easy to collect a large number of individual contributions within a short time period. One example from the previous chapter is Deliberative Polling, which illustrate how political discussions between representatives from the whole populations are synchronized into a final aggregated quantitative result. Another example is the Delphi method that aims to aggregate a comprehensive solution through several rounds of voting by using supermajority rule. When votes or judgements are stored in an online system, this makes it possible to collect asynchronous contributions within a limited time frame. For example, citizen science projects like Galaxy Zoo enable volunteers to 
do different microtasks and the results are afterwards synchronized through different averaging techniques. Crowdfunding sites like Kickstarter illustrate synchronization by donating money to different projects. The use of money permits more differentiated contributions than equal voting. The main difference today is that the voting and the aggregation of results are conducted automatically.

\subsubsection{The Evolution of Pinpointed Swarm Problem Solving}

Because pinpointed swarm problem solving attempts to identify the best solution among many other proposed solutions, it is likely that this type of problem solving motivated human groups to broaden their outreach by communicating with strangers. The establishment of premodern trade systems is one example of how humans began to communicate beyond their own band. This trade primarily exchanged valuable artifacts across long distances and established social practices that made more knowledge sharing possible, leading to new types of problem solving between groups. This extension in outreach through trade provided access to a much larger degree of informational diversity, and increased knowledge sharing would further amplify the human capability to solve different problems collectively. Strangers were increasingly regarded as potential resources in a trade network. Similar artifacts like the Venus figurine have been found across large areas, indicating the presence of shared myths and values among many different groups. As a rudimentary form of pinpointed swarm problem solving, premodern trade solves the "problem" of getting access to valuable artifacts that other groups own. The key factor is the ability to trust strangers. Strangers were gradually becoming something different because human self-awareness was emerging.

The next important milestone in pinpointed swarm problem solving can be located to the Athenian democracy, which developed institutions that opened up for a multitude of pinpointed swarm problem solving practices by bringing diverse people together.

While premodern trade (and large gatherings) started as informal exchange of knowledge and resources between groups, the Council of 500 in Athens stands out as an example of a carefully designed plan to utilize all the knowledge in a large population in a more effective way. This institution functioned as a "sensor network" by establishing social ties between individuals from all over the Athenian territory. Groups who previously had been strangers to each other were brought together within the framework of a common identity. 
With time, a line of human interaction has evolved from no stranger interaction, to informal stranger interaction, and then to formalized stranger interaction through intentionally designed social networks. This first happened in the Athenian institutions that aimed to bring together people who were dispersed over a wide territory. Every tribe was represented by one third of coastal demes, inland demes, and city demes, and representatives from all these tribes worked together solving public problems in Athens for a period of one year. The rotation of councilors every year was designed to continuously link together new groups of people. By being together, the councilors would learn about other demes. The geographically representative network maximized environmental information and strengthened the capacity to utilize sources of information from a large segment of the Athenian population.

With the emergence of a global online setting, the "territory" has become so much larger, but the goal is still to utilize expertise to pinpoint the best solution. Both innovation contests and the citizen science game Foldit illustrate how companies and academic communities reach out to a large number of unknown others in an attempt to identify the single best solution (see Chapter 2). Although there are specific individuals or small group who produce solutions, it is the informal knowledge sharing and performance of the whole Foldit community that makes the continuous production of pinpointed solutions possible.

Another interesting example from the offline setting are hackathons. A large group of individuals meets in an offline setting to solve a problem with a short time period. There will be predefined specific goals or objectives, but the problem-solving process will be more reminiscent of a marketplace or bazaar. It is characterized by a large physical setting where many informal interactions are happening at the same time in a transparent environment. When information is "offloaded" in the environment, others can potentially get access to the same information. There is a loose control of the interactions, but all participants share the conception that they must solve the challenge within a short time period. Although people who meet in this context are strangers to each other, they are still interested in the same topic, which makes it easier to interact with each other. A multitude of qualitative contributions is produced and some are expected to be relevant outputs that identify the best solutions. These will be awarded prizes at the end of the hackathon.

The IdeaRally is another example of an innovation contest that is organized as a large gathering, bringing together competent strangers together from all parts of the world (see Section 2.2). In this setting with 
many parallel ongoing activities, a number of different solutions can be developed at the same time, but only some will be selected in the end. A large pool of expertise provides a wider access to ideas compared with a small group with limited expertise. As we can see, there is today more interest in finding out how one can utilize large gatherings to identify the best solutions within a short time period.

In ancient Athens, pinpointed swarm problem solving was also used in different types of contests; voting in the Assembly was used to award citizens prizes and honorary decrees such as the best rethor of the year, or a prize to the best executive group of 50 in the Council. It illustrates that competitions were to some degree used to motivate performances of societal value. Modern CI will also utilize the same mechanisms through innovation contests. By involving unknown others or outsider expertise, this can potentially increase idea diversity. It can be compared to finding the "needle in the haystack" by recruiting a large number of contributors. Only the persons who think they can solve the problem will respond to the call. In this approach, companies pick the best solutions instead of the best people:

If you look at it from the point of view of a company they can spend a lot of time interviewing people to try and put a team together. They give them salaries and maybe they come up with the solution and then again maybe not. Instead of them going out and trying to find the best people to solve the problem, they can get a lot of people solving it and then pick the best solution rather than trying to pick the best people.

The person who provides the best solution may differ from problem to problem. When the problems are complex, the person who provides the solution can be unexpected. The solvers are not necessarily where you might expect them to be. By recruiting a large number of potential problemsolvers, this increases the likelihood of identifying a better solution because the diversity of proposals increases. Another example of pinpointing solutions is by using online leaderboards. For example, the Foldit game use many leaderboards to motivate participation and provide information about the solutions that are currently the best ones (see Section 2.3).

Furthermore, another example of pinpointed swarm problem solving in ancient Athens is the annual ostracism vote. If there were more than 6,000 votes in the first voting round, the person with the highest number of votes in the second round was exiled. There was no deliberation, only the vote. Although this voting system pinpoints the worst person, the logic is the same as voting for the best solution or person. By getting rid of one person, it was assumed that this would be beneficial for the Athenian society in 
general. In modern CI, there are not so many similar examples. However, disaster management resembles ostracism in first maximizing environmental information about an area, and then pinpointing the worst area that is most in need of help.

From a systemic perspective, ancient Athens was able to design a lottocratic political system that created many "winners" all the time. Most of the public positions, such as appointments of a magistrate (public official), juror, or councilor were based on selection by lot. Any citizen had the right to participate in decision-making, serve in public office, and could join the lottery. Most individuals would eventually win this lottery because there were so many citizen positions. Even the Council of 500 organized their work as a lottery. Leadership was rotated among 50 persons from one tribe each month. They were pinpointed to rule through random sampling. All groups would eventually "win" the honor of being leaders. By letting most councilors get the opportunity to be in charge, they would also be motivated to learn more about the Athenian governmental system. In addition, a majority of the councilors would through a daily lottery win the opportunity to be "president of Athens" for one day.

Historically, the challenge of finding the right person that can solve a problem has not been easy. The ingenious invention of Athens was instead to enable everyone to become "winners." The rotating system allowed more citizens to be part of the democratic institutions in Athens and increase their knowledge through active participation. The constant rotation ensures diversity, inclusion, and fair selection of candidates. It stimulates "heterogeneous social interaction" through the design of a multitude of groups and meetings between people who did not know each other from before, but still would engage in important societal work together. In the previous chapter, Deliberative Polling comprise a modern example of lottocratic selection, which appears to be underutilized today.

\section{Note}

I Kleroterion - machine that selected the leaders of citizens of Athens. https:// www.youtube.com/watch?v=IDhgkqJCIBA 